ПАРМА Роман Васильевич - кандидат политических наук, доцент департамента политологии факультета социальных наук и массовых коммуникаций Финансового университета при Правительстве РФ (125993, Россия, г. Москва, ГСП-3, Ленинградский пр-кт, 49; rvparma@таil.ru) ДАВЫДОВА Мария Александровна - лаборант-исследователь Центра политических исследований Финансового университета при Правительстве РФ (125993, Россия, г. Москва, ГСП-3, Ленинградский пр-кт, 49; marchikdavydova@mail.ru)

КАЩЕНКО Татьяна Леонидовна - кандидат философских наук, ведущий научный сотрудник департамента политологии факультета социальных наук и массовых коммуникаций Финансового университета при Правительстве РФ (125993, Россия, г. Москва, ГСП-3, Ленинградский пр-кт, 49; tanyakashch@mail.ru)

\title{
ПРОТЕСТНАЯ МОБИЛИЗАЦИЯ ГРАЖДАН НА ЦИФРОВОЙ ПЛАТФОРМЕ ТІКТОК В ХОДЕ ВЫБОРОВ В ГОСУДАРСТВЕННУЮ ДУМУ РОССИИ 2021 г.
}

Аннотация. В статье представлены результаты прикладного исследования цифровой платформы TikTok как площадки протестной мобилизации пользователей. Методика исследования базируется на гибридной стратегии, сочетающей социально-медийный анализ и когнитивное картирование. В ходе исследования было выявлено, что в электоральном цикле 2021 г. TikTok консолидировал существенный сегмент информационного потока, делегитимирующего процесс и результаты выборов. Массированный цифровой поток, нацеленный на формирование установок недоверия уграждан, был сформирован посредством применения манипулятивных технологий, системы хэштегов цифровой платформы площадки и разнообразных форматов подачи материалов.

Ключевые слова: социально-медийный анализ, когнитивное картирование, политические протесты, делигитимация выборов, цифровая платформа, TikTok

\begin{abstract}
Исследование выполнено при финансовой поддержке РФФИ и ЭИСИ в рамках научного проекта №21-011-33041 «Цифровые платформы как инструмент мобилизации протестных настроений граждан Республики Беларусь и Российской Федерации в 2020-2021 г2.».
\end{abstract}

Постановка проблемы. Массовые политические протесты 2020 г., масштабные акции против результатов президентских выборов в Белоруссии и смены руководства в Хабаровском крае стали источником роста протестных настроений россиян [Бродовская, Давыдова, Еремин 2021]. Выборы в Государственную думу РФ 2021 г. использовались оппозиционными силами для провоцирования протестного движения и дестабилизации политической ситуации. Одной из площадок мобилизации протеста в ходе избирательной кампании стал сервис коротких видеороликов $T i k T o k^{1}$. Данная цифровая платформа позволила сформировать интенсивный информационный поток, показав широкие возможности использования разнообразных технологий, форматов и инструментов мобилизации протеста и перевода онлайн-активности в офлайн.

Приближение Единого дня голосования подстегивало расширение протест-

1 Фактор TikTok: почему ролики про Навального и протест заполнили соцсеть. - $D W$. 2021. Доступ: https://www.dw.com/ru/faktor-tiktok-pochemu-roliki-pro-navalnogo-i-protestzapolnili-socset/a-56407464 (проверено 12.01.2022). 
ного информационного потока. Оппозиция предприняла попытку формирования установок недоверия к избирательному процессу, привлечения к участию в протестном голосовании и мобилизации недовольства, следуя белорусскому сценарию, после обнародования результатов выборов. При этом политическим партиям не удалось сформировать конкурентный конвенциональный информационный поток, который мог бы транслировать альтернативные дискурсы в цифровой среде и формировать установки лояльности к избирательной системе [Бродовская, Зворыгин, Лукушин 2021]. В этой связи актуализировался вопрос о возможностях цифровой платформы TikTok для протестной мобилизации: механизмах, технологиях, приемах, позволяющих осуществлять оперативную масштабную мобилизацию различных групп аудитории.

Теоретико-методологическая основа исследования. Теоретическая основа включает в себя несколько направлений теорий и концепций. Первое направление нацелено на осмысление специфики сетевого взаимодействия. М. Кастельс отмечал сетевой характер сообществ, строящихся на основе выбора и стратегии социальных действий [Кастельс 2004]. Б. Уэллман рассматривал различные сообщества, определяя их как сети социальных взаимодействий, поддержки, обмена информацией, объединенные чувством принадлежности к группе [Wellman 1983]. Г. Равид и В. Сорока изучали социальные сети с позиции формирования социального капитала [Rafaeli, Ravid, Soroka 2004]. Вторая группа концепций составляет теорию общественных движений. Г. Блумер выделяет как мотивацию участия в общественных движениях культурные сдвиги, изменения социальных норм и ценностей [Blumer 1969]. Н. Смелзер выделил критерии формирования структуры общественного движения, среди которых проводимость, напряженность, генерализованные убеждения, ускоряющие факторы, мобилизованные группы, социальный контроль [Смелзер 1994]. В рамках теории относительной депривации причиной роста социальной напряженности и протестной активности является рост ожиданий в условиях ограничения возможностей для их реализации [Gurr 1970]. Третье направление - теория мобилизации ресурсов. Дж. Маккарти и М. Зальд отмечают, что социальные движения формируются на основе потенциальных возможностей организации и индустрии общественных изменений [Zald, McCarthy 1987: 15-67]. Четвертое направление представлено теорией политических протестов. Ч. Тилли, С. Тарроу и Д. Макадем отмечают, что мобилизация политического протеста осуществляется на основании фреймов, которые позволяют маркировать события в таких категориях, как опасные, несправедливые и т.д. [Mcadam, Tarrow, Tilly 2004]. Пятый блок представлен теорией психологии влияния Р. Чалдини, концентрирующегося на изучении особенностей индивидуального и коллективного влияния [Чалдини 2021].

Также необходимо упомянуть актуальные отечественные и зарубежные исследования в сфере мобилизации и модерации протестной активности через социальные медиа. Так, ряд исследователей отмечают, что на политические предпочтения влияют общественные движения и специфика политических коммуникаций [Oskooii, Lajevardi, Collingwood 2021]. В ходе протестной деятельности цифровые платформы используются для обмена информацией, необходимой для координации протестов, а возможности социальных медиа позволяют эффективно распространять эмоциональные сообщения, нацеленные на формирование мотивации участия в протестных акциях [Jost et al. 2018]. При этом степень вовлеченности граждан, в т.ч. в протестные и общественные движения, определяется различными факторами и усиливается применением аффективных приемов [Skoric et al. 2016]. Исследователи Е.В. Бродовская, Р.В. Пырма, А.Ю. Домбровская, рассматривая общественный активизм рос- 
сийской молодежи, зафиксировали переход гражданской и политической онлайн-активности в пространство социальных медиа [Бродовская, Пырма, Домбровская 2020]. В.Ш. Сургуладзе отмечает специфику информационного противоборства в социальных сетях в контексте перевода онлайн-активности в офлайн, выявляя риски интеграции социальных медиа в политические процессы - изменения коллективной психологии, мотивации, поведенческих паттернов граждан [Сургуладзе 2020].

Методика. Для изучения особенностей использования цифровой платформы TikTok для протестной мобилизации граждан в России и Белоруссии в 2020-2021 гг. использовалась гибридная стратегия эмпирического исследования. На первом этапе было реализовано когнитивное картирование контента на платформе TikTok. Когнитивное картирование проводилось по хэштегам «выборы2021», «19сентября», «Госдума2021», «ДЭГ». Датасет составил 450 роликов. Анализ позволил установить содержательные характеристики публикуемого контента, триггеры и дискурсы, а также применяемые технологии мобилизации. На втором этапе был проведен социально-медийный анализ активности по хэштегам: основной инструмент - онлайн-сервис для аналитики контента Popsters. Данная методика позволила выявить динамические и количественные характеристики протестных информационных потоков о выборах. Интервал выгрузки 01.01.2021-31.10.2021.

Результаты исследования. Результаты социально-медийного анализа показывают, что TikTok стал одной из основных площадок по распространению протестного дискурса о выборах. Наиболее популярным протестным хэштегом о выборах стал хэштег «выборы2021». Количественные показатели активности демонстрируют, что данная тема получила масштабное распространение в рамках цифровой платформы. При этом работа в рамках нескольких базовых хэштегов позволила сформировать единый информационный поток, наполненный дискурсами о нелегитимности выборов, отсутствии конкуренции, а также потенциальных фальсификациях.

Протестный информационный поток о выборах получил большую сетку распространения, а также активность пользователей, которая отразилась в числе лайков и репостов. Специфика TikTok обеспечила масштабное распространение видеоконтента по разным пользовательским сегментам.

Таблица 1

Количественные характеристики протестного информационного потока о выборах в Государственную думу РФ 2021 г.

\begin{tabular}{|l|c|c|c|c|}
\hline \multicolumn{1}{|c|}{ Хэштег } & Лайки & Репосты & Комментарии & Просмотры \\
\hline Выборы2021 & 14656846 & 1247412 & 609471 & 271242528 \\
\hline Госдума2021 & 614902 & 22822 & 20484 & 9817823 \\
\hline 19сентября & 478910 & 42477 & 8524 & 5253700 \\
\hline ДЭГ & 10579 & 242 & 377 & 588274 \\
\hline
\end{tabular}

Результаты когнитивного картирования позволили установить основные особенности содержательного наполнения протестного информационного потока в TikTok. Более половины протестных публикаций в TikTok характеризуются наличием прямых указаний к действиям. Публикации подобного типа содержат конкретные инструкции и призывы к действиям: осуществлять про- 
тестное голосование, не доверять официальным результатам выборов, быть готовым к массовым фальсификациям. В совокупности с манипулятивными технологиями, аудиальным сопровождением и использованием ярких эмоциональных образов мобилизующие приемы становятся инструментом перевода онлайн-активности в офлайн. Содержательные характеристики контента протестного информационного потока о выборах в Государственную думу РФ 2021 г. показывают, что мобилизующие приемы содержат больше (52\%) прямых указаний к действиям.

При этом в целом около $60 \%$ публикаций характеризуются высокой степенью конвенциональности. Они не призывают кдестабилизации политической ситуации или силовой трансформации политического режима. Конвенциональный контент TikTok сосредоточен на формировании установок нелегитимности голосования, активизации оппозиционного голосования, а также выражении поддержки политзаключенным и оппозиции. Несмотря на высокий мобилизационный потенциал, модераторы протестных информационных потоков на данной площадке формируют лояльность в отношении оппозиции и протеста, не предпринимая попыток радикализировать движение. Функционал TikTok позволяет использовать платформу для формирования протестных установок, распространения оппозиционных дискурсов. Перевод онлайн-активности в офлайн осуществляется в рамках цифровой платформы Telegram, что подтверждают данные когнитивного картирования, демонстрирующие высокую степень неконвенциональности публикаций.

Содержательный анализ контента показывает, что в протестном информационном потоке Telegram о выборах превалируют инструкции по конкретным действиям: протестному голосованию, формам демонстрации несогласия с выборами, возможным действиям по контролю за ходом выборов. Доля протестного контента Telegram, содержащая прямые указания к действиям, составляет около $50 \%$. Контент данной площадки существенно отличается от TikTok направлениями призывов. Мессенджер Telegram формирует конкретные инструкции по действиям в офлайн-среде, а не только модели восприятия происходящих событий. Содержательные характеристики контента протестного информационного потока о выборах в Государственную думу РФ 2021 г. в Telegram указывают на наличие прямых указаний на действия и абсолютное доминирование (65\%) неконвенциональных сообщений.

Спецификой цифровой платформы TikTok является комплексное применение приемов ценностного воздействия. Содержание большинства публикаций выстраивается на основании использования эмоциональных сюжетов, таких как недопущение оппозиционных кандидатов к участию в выборах, демонстрация актов фальсификации, безальтернативность выборов, социально-экономические проблемы, политические заключенные. Аффективные приемы ценностного воздействия позволяют осуществлять воздействие на эмоции пользователей, формируя сочувствие и солидарность с участниками протестов.

Формирование протестного контента происходит на основании применения различных манипуляционных технологий. Наиболее часто используются приемы ценностного подчинения и эмоциональной стереотипизации. Ценностное подчинение позволяет транслировать универсальные ценности, образы и установки. Эмоциональная стереотипизация позволяет конструировать модель восприятия событий на основании пренебрежения к политическому режиму, органам государственной власти, политическим решениям на основании фиксации установки на отрицательное восприятие событий. Применение данных технологий позволяет вовлекать пользователей в информационные потоки о протестах, формировать лояльность к оппозиции и протестующим, а также 




- Аффективные — Смешанные Ш Рациональные

Рисунок 1. Приемы ценностного воздействия контента протестного информационного потока о выборах в Государственную думу РФ 2021 г.

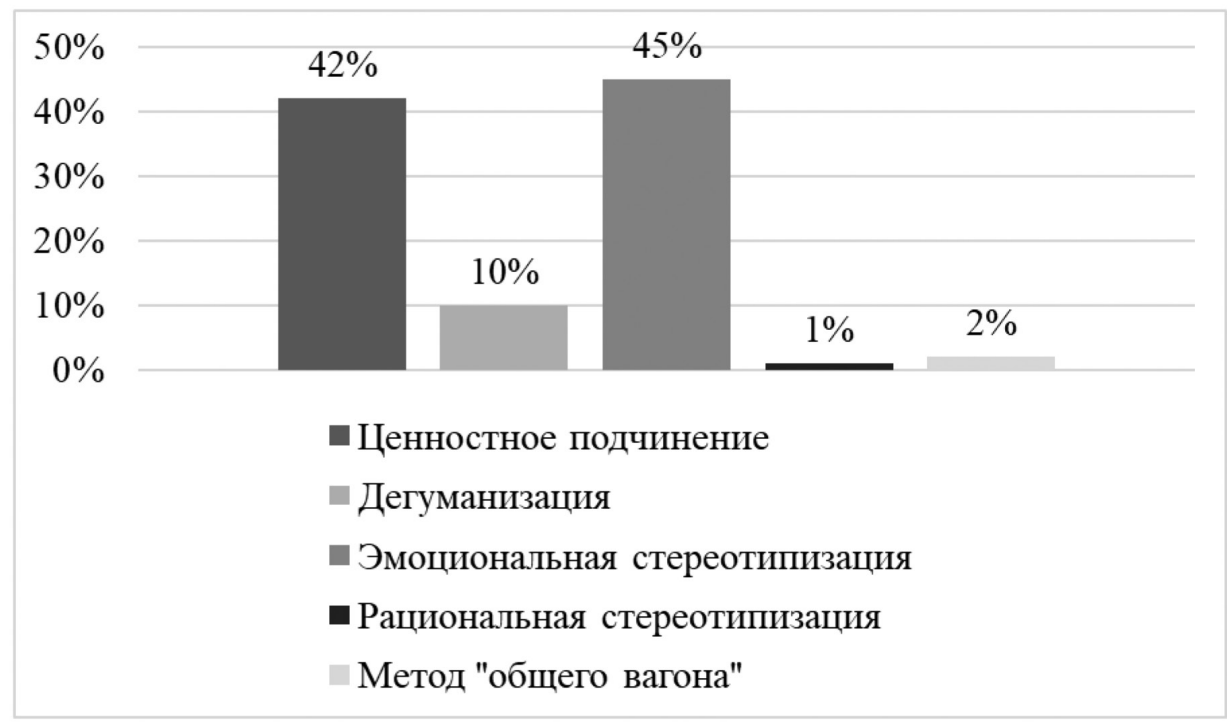

Рисунок 2. Приемы формирования дискурса протестного информационного потока о выборах в Государственную думу РФ 2021 г.

оперативно распространять оппозиционные дискурсы, в данном случае дискурсы делегитимации, выстраиваемые на основании эмоционального воздействия.

Заключение. По результатам исследования протестной мобилизации граждан на цифровой платформе TikTok в ходе выборов в Государственную думу РФ 2021 г. можно сделать следующие заключения.

Во-первых, TikTok стал одной из основных площадок распространения протестных информационных потоков о выборах. Широкая пользовательская 
база, интуитивная система формирования сетей через хэштеги, специфика формата, аудиовизуальных технологий позволили сформировать масштабный информационный поток, который на протяжении полугода осуществлял массированное воздействие на разные группы пользователей, основная цель которого - формирование установок о нелегитимности выборов, подрыв доверия к ним.

Во-вторых, алгоритмы TikTok позволяют работать с разными группами пользователей, ориентируясь на актуальные для них триггеры, дискурсы, проблемы. Так, дифференциация информационного потока по типу дискурсов (политических, протестных, социально-экономических) позволила формировать релевантный поток для каждой группы пользователей.

B-третьих, специфика функционирования TikTok позволяет манипулировать установками пользователей через различные технологические приемы. Площадка формирует конкретную модель восприятия событий, репрезентирующую протестные события с позиции лояльности.

В целом цифровая платформа TikTok обладает масштабным потенциалом как для первичной протестной мобилизации, так и для подкрепления протестных установок. Совместное использование с другими цифровыми площадками позволяет контрэлитам решать задачи, связанные с оперативной мобилизацией вне зависимости от первичного протестного триггера.

\section{Список литературы}

Бродовская Е.В., Давыдова М.А., Еремин Е.А. 2021. Пролонгированные политические протесты в России и Республике Беларусь летом-осенью 2020 года: референтность российской аудитории социальных медиа. - Гуманитарные науки. Вестник Финансового университета. №1. С. 6-13.

Бродовская Е.В., Зворыгин Р.В., Лукушин В.А. 2021. Сравнительный анализ цифровых коммуникаций и новых партийных акторов в России, 2020 г. - Вестник Московского государственного лингвистического университета. Общественные науки. № 2. С. 36-52.

Бродовская Е.В., Пырма Р.В., Домбровская А.Ю. 2020. Гражданский активизм молодежи России: структура ролей, факторы формирования установок, триггеры роста протестного потенциала. - Гуманитарные науки. Вестник Финансового университета. № 6. С. 39-48.

Кастельс М. 2004. Галактика Интернет. Размышления об Интернете, бизнесе и обществе. Екатеринбург: У-Фактория. 328 с.

Смелзер Н. 1994. Социология. М.: Феникс. 688 с.

Сургуладзе В.Ш. 2020. Социальные медиа - инструменты социальнополитической дестабилизации общества: уроки, тенденции, перспективы. Гуманитарные науки. Вестник Финансового университета. №1. С. 6-13.

Чалдини Р. 2021. Психология влияния. М.: Эксмо. 416 с.

Blumer H. 1969. Collective Behavior. - Principles of Sociology (ed. by A.M. Lee). N.Y., NY: Barnes and Noble. P. 165-221.

Gurr T.R. 1970. Why Men Rebel. P.: Princeton University Press. 407 p.

Jost J.T., Barbera P., Bonneau R., Langer M., Metzger M., Nagler J., Sterling J., Tucker J.A. 2018. How Social Media Facilitates Political Protest: Information, Motivation, and Social Networks. - Political Psychology. Vol. 39. Is. 11. P. 85-118.

Mcadam D., Tarrow S., Tilly C. 2004. Dynamics of Contention. C.: Cambridge University Press. 387 p.

Oskooii K.A.R., Lajevardi N., Collingwood L. 2021. Opinion Shift and Stability: The Information Environment and Long-Lasting Opposition to Trump's Muslim Ban. - Political Behavior. Vol. 43. Is. 11. P. 301-337. 
Rafaeli S., Ravid G., Soroka V. 2004. De-lurking in Virtual Communities: A Social Communication Network Approach to Measuring the Effects of Social and Cultural Capital. - Proceedings of the 37th Hawaii International Conference on System Sciences.

Skoric M., Zhu Q., Goh D., Pang N. 2016. Social Media and Citizen Engagement: A Meta-Analytic Review. - New Media \& Society. Vol. 18. Is. 9. P. 1817-1839.

Wellman B. 1983. Network Analysis: Some Basic Principles. - Sociological Theory. Vol. 1. P. 155-200.

Zald M.N., McCarthy J.D. 1987. Social Movements in an Organizational Society: Collected Essays. N.J.: Transaction Publishers. 435 p.

PARMA Roman Vasil'evich, Cand.Sci. (Pol.Sci.), Associate Professor of the Department of Political Science, Faculty of Social Sciences and Mass Communication, Financial University under the Government of the Russian Federation (49 Leningradsky Ave, GSP-3, Moscow, Russia, 125993; rvparma@mail.ru)

DAVYDOVA Maria Aleksandrovna, Laboratory Researcher at the Center for Political Studies, Financial University under the Government of the Russian Federation (49 Leningradsky Ave, GSP-3, Moscow, Russia, 125993; marchikdavydova@ mail.ru)

KASHCHENKO Tatiana Leonidovna, Cand.Sci. (Philos.), Leading Researcher at the Department of Political Science, Faculty of Social Sciences and Mass Communication, Financial University under the Government of the Russian Federation (49 Leningradsky Ave, GSP-3, Moscow, Russia, 125993; tanyakashch@mail.ru)

\section{PROTEST MOBILIZATION OF CITIZENS ON THE DIGITAL PLATFORM TIKTOK DURING THE ELECTIONS TO THE STATE DUMA OF RUSSIA IN 2021}

\footnotetext{
Abstract. The article presents the results of an applied research of the digital platform TikTok as a platform for protest mobilization of users. The research methodology is based on a hybrid strategy that combines social media analysis and cognitive mapping. The study reveals that in the electoral cycle of 2021, TikTok had consolidated a significant segment of the information flow, delegitimizing the process and election results. A massive digital stream aimed at creating attitudes of distrust among citizens was formed using manipulative technologies, the hashtag system of the digital platform, and various formats for presenting materials.
}

Keywords: social media analysis, cognitive mapping, political protests, election delegitimating, digital platform, TikTok 